\title{
REVITALISASI JEMBATAN DESA SEBAGAI AKSES AKTIVITAS PEREKONOMIAN DESA BANGPINDAH KECAMATAN GALIS BANGKALAN
}

\author{
Mudarris, Imamul Muttaqin, Zainal Hakim \\ STAI Darul Hikmah Bangkalan \\ darrisnice@gmail.com, ,miliadiarisandhi@darul-hikmah.com, \\ azhari@darul-hikmah.com
}

\begin{abstract}
ABSTRAK
Desa Bangpendah merupakan salah satu dari desa yang berada di kecamatan Galis kabupaten Bangkalan. Desa bangpendah merupakan desa yang sangat asri yang terdiri dari tiga dusun, yakni: Dusun Bangpendah, Bicabbih dan Nangsokah. Desa Bangpendah memiliki potensi-potensi alam maupun manusia yang bagus. Desa bangpendah memiliki luasa 440,4 Ha. Dan memiliki lebih dari 1.000 jiwa dari anak-anak sampai dewasa. Semua penduduk yang berada di Desa mayoritas melakukan perekonomian dengan berkebun, bercocok tanam dan menjadi pedagang di Pasar yang ada di Kecamatan Tanah Merah dan Galis. Untuk kegiatan tersebut, tentunya jembatan yang berada di Desa Bangpindah menjadi satu satunya harapan masyarakat bangpindah untuk melakukan kegiatan perekonomiannya. Hadirnya mahasiswa KKN di Desa bangpindah ini membawa harapan besar masyarakat Desa Bangpindah dalam melakukan kegiatan perekonomian, hal ini terbukti dengan adanya revitalisasi jembatan yang semula kumuh dan tidak dapat diakses dengan baik, namun setelah dilaksanakan program revitaliasi ini, jembatan menjadi indah, bagus, yang semula masyarakat Desa Bangpindah malas untuk melewati Jembatan ini, dengan adanya revitalisasi jembatan desa, sekarang jembatan tersebut menjadi satu-satu akses yang dilewati masyarakat dalam melakukan kegiatan ekonominya.
\end{abstract}

Kata Kunci: revitalisasi, Jembatan Desa, perekonomian 


\section{A. ANALISIS SITUASI}

Desa Bangpendah merupakan salah satu dari desa yang berada di kecamatan Galis kabupaten Bangkalan. Desa bangpendah merupakan desa yang sangat asri yang terdiri dari tiga dusun, yakni: Dusun Bangpendah, Bicabbih dan Nangsokah. Desa Bangpendah memiliki potensi-potensi alam maupun manusia yang bagus. Desa bangpendah memiliki luasa 440,4 Ha. Dan memiliki lebih dari 1.000 jiwa dari anakanak sampai dewasa. Desa bangpendah berdekatan dengan desa banjar sebelah selatanya, Desa Bukoran sebelah utaranya, Desa Jangkar sebelah baratnya, dan Desa Sadah disebelah timurnya.

Dari luas Desa tersebut terdapat akses masyarakat dalam melakukan kegiatan ekonomi, yaitu sebuah jembatan yang menghubungkan masyarakat Desa Bangpindah dengan perekonomian di sekitarnya.

Keberadaan jembatan di Desa tersebut, sangat kurang menjadi perhatian bagi masyarakat Bangpindah.

Adanya Mahasiswa STAI Darul Hikmah yang melaksanakan kegiatan KKN di Desa tersebut berinisiatif untuk merevitalisasi jembatan agar tidak hanya menjadi akses dalam perekonomian, serta menjadi sebuah icon kebanggaan bagi masyarakat Desa Bangpindah.

Dari letak geografisnya, Desa Bangpendah berpenduduk 1.612 jiwa dengan jumlah kepala keluarga sebanyak 3000 kepala keluarga. Yang mana terdapat $51 \%$ berjenis kelamin laki-laki dan sebanyak $49 \%$ berjenis kelamin perempuan. Sehingga, jumlah penduduk berdasarkan jenis kelamin laki-laki dan perempuan secara berturut-turut sebebanyak 820 jiwa dan 792 jiwa.

Semua penduduk yang berada di Desa mayoritas melakukan perekonomian dengan berkebun, bercocok tanam dan menjadi pedagang 
di Pasar yang ada di Kecamatan Tanah Merah dan Galis. Untuk kegiatan tersebut, tentunya jembatan yang berada di Desa Bangpindah menjadi satu satunya harapan masyarakat bangpindah untuk melakukan kegiatan perekonomiannya.

Mahasiswa KKN yang pertamakali menjadi target pengabdiannya adalah dengan melakukan revitaliasi jembatan Desa, sehingga besar harapannya adalah dapat membantu pergerakan perekonomian masyarakat Bangpindah baik dalam pertanian, bercocok tanam, atau perdagangan. Untuk itu pengabdian yang diambil adalah "Revitalisasi Jembatana Desa Sebagai Akses Aktivitas Perekonomian Desa Bangpindah Kecamatan Galis Bangkalan".

\section{B. STRATEGI PELAKSANAAN PROGRAM}

Strategi adalah penentuan dari tujuan dasar jangka panjang dan sasaran sebuah perusahaan, dan penerimaan dari serangkaian tindakan dan alokasi dari sumber-sumber yang dibutuhkan untuk melaksanakan tujuan tersebut. Dari definisi ini jelas bahwa tujuan merujuk pada hasil akhir sedangkan strategi merujuk pada cara yang ditempuh untuk mencapai hasil akhir. Setiap kegiatan pasti memerlukan strategi untuk mencapai tujuan yang diinginkan.

Adapun strategi pencapaian program meliputi

\section{Perencanaan}

Pada tahapan ini, mahasiswa KKN melakukan koordinasi dengan segenap perangkat Desa dan tokoh masyarakat bangpindah, dimana tahapan ini selalu dikedepankan agar terjalinnya hubungan yang harmonis dari mahasiswa KKN dan segenap masyarakat Desa Bangpindah. 


\section{Pengorganisasian}

Pengorganisasian adalah langkah pengaturan agar program berjalan sesuai dengan harapan dan tidak tumpang tindih. Dalam pengorganisasian ini dilakukan penentuan siapa penanggungjawabnya, berapa biayanya, penentuan tahapantahapan pelaksanaan, dan penentuan penyelesaian program.

Pada tahapan ini, Kepala Desa dan Aparaturnya memberikan hak sepenuhnya kepada mahasiswa KKN, namun tentunya setiap pelaksannannya selalu melaporkan kepada Kepala Desa bangpindah, sehingga capaian penyelesainnya dapat sesuai dengan jadwal yang telah dikorrdinasikan sebelumnya.

\section{Pelaksanaan}

Pelaksanaan dilaksanakan sesuai dengan program yang dicanangkan dalam pengorganisasian dengan memperhatikan kondisi setempat ( tempat, waktu, biaya, sasaran ) sehingga program dapat terlaksana dengan baik dengan mendapat dukungan penuh dari peserta dan menghasilkan out put yang memuaskan.

Pada tahapan ini, Mahasiswa KKN membuat jadwal pelaksanaan yang nantinya dapat membantu agar program revitalisasi ini selesai sesuai dengan jadwal yang telah dikoordinasikan, sehingga hal-hal yang tidak diinginkan dalam pelaksaan revitalisasi ini dapat diminimasir dengan sebaik-baiknya.

\section{Pemantauan/ Kontrol}

Pemantauan/kontrol. Ini dilakukan agar pelaksaan program tidak melenceng dari rencana. Setiap tahap pelaksanaan program selalu dikontrol, baik oleh aparatur Desa, maupun masyarakat Bangpindah, sehingga apabila ditemukan kesalahan, baik yang 
berhubungan dengan penanggung jawab, peserta, biaya maupun yang lain, segera dapat diperbaiki sesuai dengan rencana.

Pada tahapan ini, Kontrol yang dilakukan oleh Aparatur Desa sangat membantu dalam menyelesaikan tahapan demi tahapan, dan hasil yang dinginkan sejak direncanakan dapat terealiasi, sehingga dapat menyesuaikan dengan rencana awal yang dilakukan oleh aparatur Desa, masyarakat Bangpindah dan mahasiswa KKN.

\section{Evaluasi}

Evaluasi. Kegiatan ini sebagai upaya untuk mengetahui apakah program yang dicanangkan sesuai atau tidak dengan pelaksanaannya serta hasil yang dicapai. Adapun stakeholders dalam kegiatan ini adalah (a) Aparat pemerintah setempat, (b) Tokoh masyarakat, (3) Mahasiswa KKN,

Tahapan evaluasi dalam kegiatan ini dilaksanakan dalam tiga tahap, yaitu:

\section{a. Tahap perencanaan kegiatan}

Para mahasiswa pada awal kegiatan melakukan koordinasi dengan apparat Desa, Tokoh Masyarakat, guna menentukan sasaran yang akan dicapai dalam revitalisasi jembatan tersebut. Dukungan dan support yang luar biasa dari stakeholders kegiatan ini sangat memberikan manfaat, sehingga para mahasiswa dapat memberikan gambaran umum bentuk revitalisasi jembatan yang akan di.kerjakan.

\section{b. Selama proses kegiatan}

Evaluasi pada tahap ini ditujukan untuk mengetahui seberpa besar tahapan demi tahapan yang dilakukan para mahasiswa dalam menyelesaikan revitalisasi jembatan tersebut.

Untuk lebih lengkapnya, tahapan selama proses revitaliasi ini, kami gambarkan dalam bentuk table berikut: 
Tabel 1.

Pelaksaan Proses Kegiatan Revitalisasi Jembatan Desa

\begin{tabular}{|c|c|c|c|}
\hline NO & BULAN & TEMPAT & KEGIATAN \\
\hline 1 & $\begin{array}{l}5 \text { s.d. } 8 \\
\text { Oktober } 2020\end{array}$ & $\begin{array}{l}\text { Rumah Kepala } \\
\text { Desa Bangpindah }\end{array}$ & $\begin{array}{l}\text { Sosialisasi program dan } \\
\text { sekaligus pembentukan } \\
\text { pengurus dan petugas } \\
\text { dalam revitalisasi } \\
\text { jembatan }\end{array}$ \\
\hline 2 & $\begin{array}{l}9 \text { s.d. } 10 \\
\text { Oktober } 2020\end{array}$ & $\begin{array}{l}\text { Kantor Desa } \\
\text { Bangpindah }\end{array}$ & $\begin{array}{l}\text { Membeli Bahan-bahan } \\
\text { yang diperlukan untuk } \\
\text { kebutuha revitalisasi }\end{array}$ \\
\hline 3 & $\begin{array}{l}11 \text { s.d } 13 \\
\text { Oktober } 2020\end{array}$ & Jembatan Desa & $\begin{array}{l}\text { Membersihkan dan } \\
\text { membenahi Jembatan } \\
\text { sebelum dilakukan } \\
\text { revitalisasi }\end{array}$ \\
\hline 4 & $\begin{array}{l}14 \text { s.d } 19 \\
\text { Oktober } 2020\end{array}$ & Jembatan Desa & $\begin{array}{l}\text { Melakukan pengecetan } \\
\text { dan Perbaikan Jembatan }\end{array}$ \\
\hline 5 & $\begin{array}{l}20 \text { s.d } 21 \\
\text { Oktober } 2020\end{array}$ & $\begin{array}{l}\text { Rumah Kepala } \\
\text { Desa dan } \\
\text { Jembatan Desa }\end{array}$ & $\begin{array}{l}\text { Melakukan pelaporan } \\
\text { terhadap hasil yang telah } \\
\text { dicapai, yang selanjutnya } \\
\text { mendapatkan respon dari } \\
\text { Kepala Desa untuk } \\
\text { dilanjutkan dan } \\
\text { diselesaikan }\end{array}$ \\
\hline 6 & $\begin{array}{l}22 \text { s.d } 26 \\
\text { Oktober } 2020\end{array}$ & Jembatan Desa & $\begin{array}{l}\text { melanjutkan revitalisasi } \\
\text { dan menyelesaikannya } \\
\text { agar dapat dinikmati oleh }\end{array}$ \\
\hline
\end{tabular}


masyarakat desa

bangpindah

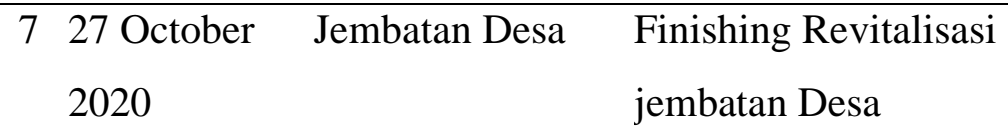

\section{c. Tahap akhir kegiatan}

Evaluasi pada akhir kegiatan ini dilakukan untuk mengukur keercapain hasil yang telah direncanakan sebelumnya. Adapun indikator keberhasilan dari kegiatan ini adalah respons positif dan kebanggan dari masyarakat Desa saat melintasi jembatan Desa Bangpindah.

\section{DISKUSI DATA}

Hadirnya mahasiswa KKN di Desa bangpindah ini membawa harapan besar masyarakat Desa bangpindah dalam melakukan kegiatan perekonomian, hal ini terbukti dengan adanya revitalisasi jembatan yang semula kumuh dan tidak dapat diakses dengan baik, namun setelah dilaksanakan program revitaliasi ini, jembatan menjadi indah, bagus, bahkan mendapat julukan dari masyarakat desa sebelah sebagai jembatan tiktok.

Bukan hanya itu, jembatan desa yang semula terlihat tidak terawat, bahkan masyarakat Bangpindah sendiripun jarang menggunakan atau melaluinya karena aksesnya yang sangat tidak baik untuk dilewati. Berikut adalah foto Jembatan Desa sebelum dilakukan revitalisasi

\section{Gambar 1}

Jembatan Desa sebelum di revitalisasi

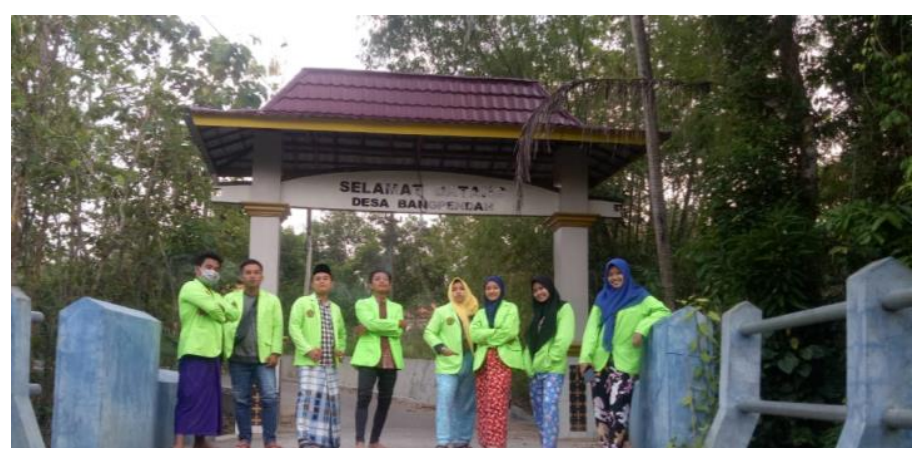


Keberadaan mahasiswa KKN di Des ini dapat merubah, dan menjadikan jembatan sebagai akses prekonomian dengan desain dan bentuk yang lebih indah dan lebihi menarik, sehingga, masyakarat desa bangpindah yang semula malas untuk melewati Jembatan ini, dengan adanya revitalisasi jembatan desa, sekarang jembatan tersebut menjadi satu-satu akses yang dilewati masyarakat dalam melakukan kegiatan ekonominya.

Berikut adalah gambar jembatan Desa sesudah mengalami revitalisasi, tampak salah satu warga masyarakat Desa Bangpindah yang sempat mengabadikannya.

\section{Gambar 2}

Jembatan Desa sesudah di revitalisasi

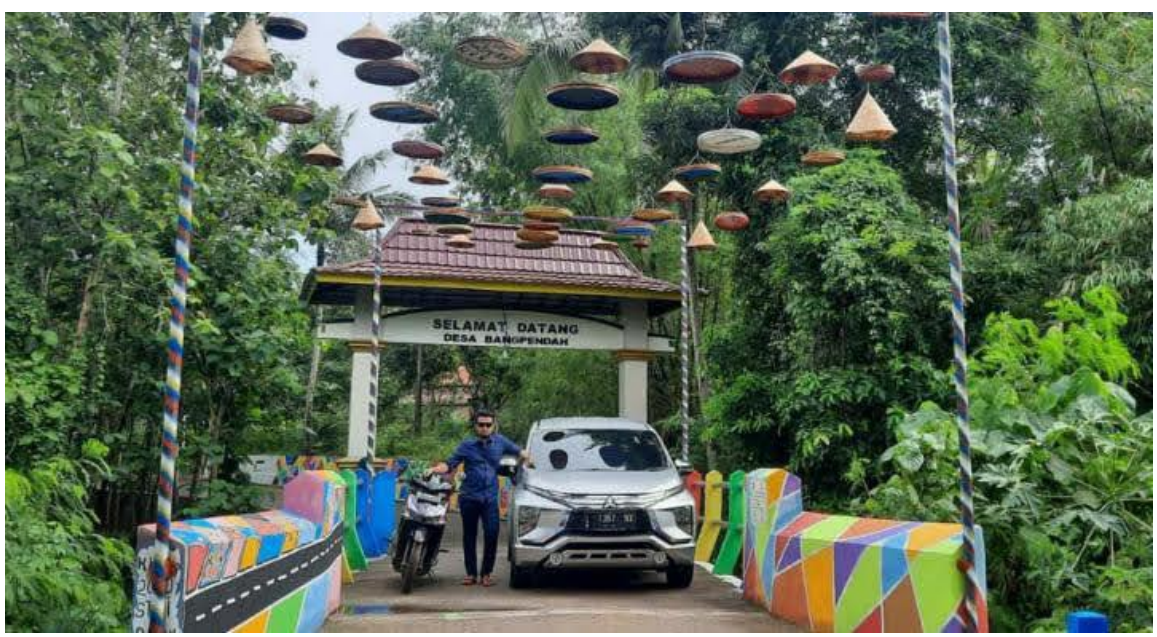

Dari hasil revitalisasi tersebut, para mahasiswa secara tidak langsung sudah mendukukung program Pemerintah pusat yang tertuang dalam Permen PUPR Nomor 31.1 Tahun 2015 pada ayat 3 yang berbunyi : "mewujudkan penguatan konektivitasnasional melalui dukungan penyediaan infrastruktur jalan yang memenuh istandar pelayanan" Mengingat begitu besarnya manfaat revitalisasi jembatan desa ini bagi masyarakat, maka setelah kegiatan program ini, jembatan tersebut harus dilestarikan dan dijaga oleh stakeholder di desa setempat sehingga terjadi kesinambungan. 
Dengan besarnya partisipasi masyarakat terhadap selesainya program ini, maka bentuk kesadaran dari semua pihak dapat membantu menjadikan jembatan tersebut sebagai jembatan yang bukan hanya untuk akses kegiatan ekonomi, namun juga untuk kepentingan lain yang bernilai positif dan bermanfaat untuk masyarakat desa bangpindah khusunya dan masyarakat sekitar pada umumnya.

Diharapkan dari kegiatan program ini juga dapat memotivasi desa-desa lain yang berada disekitar desa Bangpindah untuk menjaga dan melesatirikan jembatan Desa yang ada, agar dapat dipergunakan dengan sebaik-baiknya oleh msyarakat sekitar dan tentunya menjadi kebanggaan bagi masyarakat sekitra.

\section{KESIMPULAN}

Dengan selesainya kegitana pengabdian masyarakat di desa Bangpindah terdapat beberapa implikasi kegiatan diantaranya (1) Kondisi masyarakat desa Bangpindah sebelum direvitalisasi jembatannya melalui jalan lain yang lebih jauh jaraknya untuk melakukan kegiatan ekonomi, (2) Bentuk kegiatan yang dilakukan meliputi penyadaran akan pentingnya jembatan Desa sebagai akses kegitan perekonoimian desa sehingga dapat menjadi kebanggan Desa Bangpindah, (3) Setelah program KKN selesai, muncul kepercayaan masyarakat akan potensi diri baik secara social maupun moral, sehingga melahirkan kecintaan dan kebanggan terhadap jembatan Desa yang dapat mendukung baik dalam kegiatan perekoniomian maupun maupun sosial lainnya.

Disamping itu juga, adanya revitalisasi jembatan desa yang dilakukan oleh Mahasiswa KKN berhasil merubah pola pikir masyarakat, yang awalnya sebagai bentuk sarana yang kurang digemari, 
menjadi jembatan Desa yang dibanggakan dan dijadikan sebagai icon Desa Bangpindah.

\section{E. UCAPAN TERIMA KASIH}

Kegiatan KKN ini terselenggara berkat partisipasi serta kerjasama tokoh masyarakat dan aparatur Desa. Untuk itu kami ucapkan terimakasih sedalam-dalamnya kepada aparatur Desa Bangpindah yang mendukung dan memberikan support kepada kami, terlebih lagi kepada Kepala Desa Bangpindah yang secara khusus tidak hanya mendukung, tetapi juga membarikan bantuan dana yang dapat mengurangi beban dari para Mahasiswa KKN Desa Bangpindah.

Tak lupa lupa ucapa terimakasih terhaturkan kepada masyarakat Desa Bangpindah yang ikut serta dalam kegiatan revitalisasi jembatan Desa ini dari awal hingga terselesaikannya jembatan Desa Bangpindah. 


\section{DAFTAR PUSTAKA}

Afandi, M. H., Arifin, Z., \& Ramdhan, T. W. (2020). UPAYA PEMBERDAYAAN MASYARAKAT MELALUI PENGHIMPUNAN DANA KOINISASI DI DESA NGRONGGOT KECAMATAN NGRONGGOT KABUPATEN NGANJUK. AsSidanah: Jurnal Pengabdian Masyarakat, 2(1), 63-84.

Arbani, Inggar Rayi, and Hertiari Idajati. "Identifikasi Potensi dan Masalah dalam Revitalisasi Kawasan Sungai Kalimas di Surabaya Utara." Jurnal Teknik ITS 6.2 (2017): C180-C182.

Ariyanti, Annisa, S. T. Wisnu Setiawan, and M. Arch. Revitalisasi Permukiman Kumuh di Desa Purwogondo sebagai Kampung Wisata Minat Khusus Home Industry Tahu. Diss. Universitas Muhammadiyah Surakarta, 2017.

Akbarwati, Evi, and Putu Gde Ariastita. "Revitalisasi kawasan pelabuhan kamal di madura." Jurnal Teknik ITS 2.2 (2013): C104-C108.

BPS, 2018, Kecamatn Galis dalam Angka 2018, Bangkalan: BPS Bangkalan

TW Ramdhan, B Arisandi - Nusantara Journal of Community Engagement, 2020

Yuniar, Tria Islamiyati. Perubahan pendapatan pedagang pasar pasca revitalisasi: Studi analisis di Desa Pangalengan. Diss. UIN Sunan Gunung Djati Bandung, 2020. 